\title{
Risk factors and effects of postpartum anovulation in dairy cows
}

\author{
J. Dubuc, ${ }^{* 1,2}$ T. F. Duffield, ${ }^{\star}$ K. E. Leslie, ${ }^{*}$ J. S. Walton,† and S. J. LeBlanc* \\ *Department of Population Medicine, and \\ †Department of Animal and Poultry Science, University of Guelph, Guelph, Ontario, N1G 2W1, Canada
}

\begin{abstract}
The objectives were to identify risk factors for and to quantify the effect of postpartum anovulation on reproductive performance in dairy cows. Data from 2,178 Holstein cows in 6 commercial herds enrolled in a randomized clinical trial were used. Data on periparturient disease incidence, calving history, and body condition score were collected. Cows were examined at wk 5 postpartum for reproductive tract disease; cytological endometritis was defined as $\geq 6 \%$ polymorphonuclear cells in endometrial cytology, and purulent vaginal discharge was defined as the presence of mucopurulent or purulent vaginal discharge. Cows were followed until 300 $\mathrm{d}$ in milk (DIM) for reproductive performance. Serum nonesterified fatty acids (NEFA) concentration was measured once during the week before expected calving. Serum $\beta$-hydroxybutyrate, NEFA, and haptoglobin were measured at wk 1, 2, and 3 postpartum. Serum progesterone (P4) was measured at wk $3,5,7$, and 9 postpartum. The end of the postpartum anovulation period was defined as the first sampling time at which $\mathrm{P} 4$ was $>1 \mathrm{ng} / \mathrm{mL}$. Statistical analyses were performed using logistic regression models and Cox proportional hazard models. The prevalence of anovulation was 72 , 44,26 , and $17 \%$ at wk $3,5,7$, and 9 , respectively. Cows were classified according to their ovulatory status as having luteal function at 21 DIM (Cyc21), as having low P4 at 21 DIM but having luteal function at least once at 35 or 49 or 63 DIM (Cyc63), or being anovulatory at 63 DIM (Anov63; no samples with P4 >1 ng/ $\mathrm{mL})$. Factors associated with early ovulation (Cyc21) included season, parity, decreased haptoglobinemia, and decreased serum NEFA concentration before and after parturition. Risk factors for prolonged anovulation (Anov63) included cytological endometritis, increased haptoglobinemia, and greater serum NEFA
\end{abstract}

Received July 28, 2011.

Accepted November 21, 2011.

${ }^{1}$ Current address: Faculté de médecine vétérinaire, Université de Montréal, C.P. 5000, Saint-Hyacinthe, Québec, J2S 7C6, Canada.

${ }^{2}$ Corresponding author: jocelyn.dubuc@umontreal.ca concentrations before and after parturition. Cows classified as Anov63 had an increased median time to first breeding compared with Cyc63 (74.1 vs. 73.2 d). The effect of prolonged postpartum anovulation on median time to pregnancy was conditional on parity group; a detrimental effect was present in cows of parity $\geq 3$ (129 $\mathrm{d}$ for Cyc21, $151 \mathrm{~d}$ for Cyc63, and $180 \mathrm{~d}$ for Anov63), but no effect was observed in cows of parity $\leq 2$. Overall, these findings suggest that postpartum anovulation was associated with indicators of energy balance and uterine inflammation, and with detrimental effects on reproductive performance.

Key words: dairy cow, anovulation, risk factor, effect

\section{INTRODUCTION}

Resumption of ovarian cyclicity is essential in postpartum dairy cows for ensuring subsequent pregnancy and herd profitability. The duration of postpartum anovulation in dairy cows is variable. On average, first postpartum ovulation occurs by 30 DIM, but the distribution of DIM around this average is skewed to the right (McCoy et al., 2006). As such, the apparent prevalence of postpartum anovulation is reported to be as high as 60, 40, and $30 \%$ at 21, 49, and 60 DIM, respectively (Beam and Butler, 1997; Walsh et al., 2007; Galvão et al., 2010).

Increased severity of negative energy balance during the postpartum period and a longer interval to its nadir increased the risk and duration of postpartum anovulation (Beam and Butler, 1997, 1998). Thus, serum NEFA and BHBA concentrations may help to identify cows at greater risk of prolonged postpartum anovulation that could potentially benefit from targeted preventive therapy. Uterine infection and inflammation were associated with altered follicle growth on ovaries ipsilateral to the previous pregnancy, disruption of subsequent luteal phase duration (Mateus et al., 2002; Sheldon et al., 2002), and delayed first ovulation (Opsomer et al., 2000; Galvão et al., 2010). Cows with greater growth of uterine bacterial pathogens postpartum developed smaller first dominant follicles, which if ovulated, made smaller corpus luteum with lower circulating concentra- 
tions of progesterone (Williams et al., 2007). The effect of uterine disease on ovarian function may be mediated through the ovary, hypothalamus and pituitary (Sheldon et al., 2009). Haptoglobin (HAPTO) is an acute phase protein, an early indicator for metritis and endometritis (Huzzey et al., 2009; Dubuc et al., 2010b). Therefore, HAPTO might be associated with greater risk of prolonged postpartum anovulation.

Early postpartum ovulation ( $<21$ DIM) was associated with improved subsequent reproductive performance (Galvão et al., 2010), whereas anovulatory condition at 50 to 60 DIM was associated with decreased pregnancy rate for several months (Walsh et al., 2007; Santos et al., 2009). First ovulation occurring after 21 DIM, but before 50 DIM was detrimental to reproductive performance compared with earlier ovulation (Galvão et al., 2010). Overall, it appears that cows with early resumption of ovulation $(<21$ DIM) have the best subsequent reproductive performance (conditional on continuing a normal estrus cycle; Opsomer et al., 2000) and that cows remaining anovulatory at 50 to 60 DIM have the worst reproductive performance. Unfortunately, few of the previously mentioned studies accounted for postpartum uterine disease status, which has a major effect on reproductive performance (LeBlanc et al., 2002; Gilbert et al., 2005; Dubuc et al., 2010a). Recently, cytological endometritis (CYTO) and purulent vaginal discharge (PVD) were shown to be different manifestations of postpartum reproductive disease (Dubuc et al., 2010a) and their associations with duration of postpartum anovulation need to be explored. One field study showed that CYTO was associated with an increased likelihood of prolonged anovulation (Burke et al., 2010). The effect of anovulatory status at the start of the breeding period on culling in non-seasonal intensive production systems is unclear, but decreased reproductive performance would likely lead to increased culling in late lactation.

The first objective was to identify risk factors for early ovulation and prolonged anovulation during the postpartum period. The hypothesis was that indicators of uterine inflammation and negative energy balance would be potential predictors. The second and third objectives were to quantify the effects of early ovulation and prolonged anovulation on subsequent reproductive performance and culling, respectively. The hypotheses were that prolonged postpartum anovulation would decrease the pregnancy rate, which would increase culling in late lactation. A novel aspect was to distinguish risk factors and effects among cows that first ovulated early, cows that did not first ovulate early but that ovulated before the start of breeding period, and cows that did not ovulate before the start of the breeding period.

\section{MATERIALS AND METHODS}

\section{Experimental Design}

A total of 2,178 Holstein cows from 6 commercial dairies, including 3 in southwestern Ontario (Canada) and 3 in western New York, were enrolled in this observational study. These cows were part of a clinical trial investigating the effects of ceftiofur and prostaglandin treatments on postpartum uterine diseases and reproductive performance (Dubuc et al., 2011). Ceftiofur (ceftiofur crystalline free acid; Pfizer Animal Health, New York, NY) was used 24 h after calving and prostaglandin (dinoprost; Pfizer Animal Health) was used at $35 \pm 3$ and $49 \pm 3$ DIM. For the clinical trial, cows were classified and purposively enrolled according to risk factors for uterine disease. Cows were considered at high risk if they had twins, dystocia, or retained placenta (RP); remaining cows were classified at low risk of uterine disease (Dubuc et al., 2011). Cows were housed in freestall barns and herd size ranged from 300 to 1,000 milking cows. Participating herds were recruited based on convenience, but were required to use a monthly DHIA milk recording service. Data recorded during the study period included cow parity group (first, second, and third or greater), calving date, season of calving (winter: December to February; spring: March to May; summer: June to August; fall: September to November), DHIA test-day milk production data for the first $4 \mathrm{mo}$ of lactation, and peripartum events and diseases (twins, dystocia, RP, and metritis). Definitions of RP (failure to pass fetal membranes within $24 \mathrm{~h}$ after parturition), metritis (systemic illness including fever $>39.5^{\circ} \mathrm{C}$ with fetid vaginal discharge), and dystocia (pull necessitating $\geq 2$ people or a calfjack, taking longer than $15 \mathrm{~min}$, or veterinary assisted) were standardized at the beginning of the study. Cows diagnosed with metritis were treated with ceftiofur or procaine penicillin, as labeled by product manufacturers and according to farm protocol.

Farms were visited weekly by a technician and a veterinarian for data collection from September 2007 until November 2008. Cows were enrolled 1 wk before expected calving. A blood sample from coccygeal vessels was collected weekly (same day and time every week, but the interval from calving at sampling varied between cows by $\pm 3 \mathrm{~d}$ ) from each cow into an evacuated sterile tube without anticoagulant (Vacutainer; Becton Dickinson, Franklin Lakes, NJ) during prepartum (1 wk before expected parturition) and postpartum (wk 1, $2,3,5,7$, and 9) periods. Samples were kept chilled and allowed to clot. Samples were centrifuged at 1,400 $\times g$ for $10 \mathrm{~min}$ at $20^{\circ} \mathrm{C}$ to collect serum within $5 \mathrm{~h}$ of blood collection and were frozen at $-20^{\circ} \mathrm{C}$ until analyzed. 
Prepartum samples were tested for NEFA. Postpartum samples collected at wk 1, 2, and 3 were tested for NEFA, BHBA, and HAPTO, whereas samples collected at wk 3, 5, 7, and 9 were tested for progesterone (P4). Serum chemistry analyses were performed at the Animal Health Laboratory of the University of Guelph (Guelph, ON, Canada). The NEFA, BHBA, and HAPTO serum concentrations were quantified using an automated serum analyzer (Hitachi 911; Roche Diagnostics Corp., Indianapolis, IN). The NEFA and BHBA concentrations were determined using Randox NEFA and Randox BHBA kits (Randox Laboratories Canada Ltd., Mississauga, ON, Canada), respectively. Analytical sensitivity of NEFA and BHBA assays were $0.1 \mathrm{mmol} / \mathrm{L}$ and $15 \mu \mathrm{mol} / \mathrm{L}$, respectively. Inter- and intra-assay coefficients of variation were 3.9 and $4.1 \%$, respectively, for NEFA, and 4.9 and $4.5 \%$, respectively, for BHBA. The concentration of HAPTO in serum was determined by measuring the hemoglobin-binding capacity using a methemoglobin reagent made on-site according to a method described elsewhere (Skinner et al., 1991; Skinner and Roberts, 1994). The analytical sensitivity of the HAPTO assay was $0.03 \mathrm{~g} / \mathrm{L}$. Interand intra-assay coefficients of variation were 1.9 and $2.0 \%$, respectively. The concentration of $\mathrm{P} 4$ in serum was determined with a sequential competitive immunoassay (Immulite; Siemens, Mississauga, ON, Canada) validated for use in cattle (Martin et al., 2007). Interand intra-assay coefficients of variation were 9.6 and $7.2 \%$, respectively.

Cows were examined at enrolment and at wk 9 postpartum for BCS using a 5-point scale (Ferguson et al., 1994). Examination at wk 5 postpartum included collection of endometrial cytology samples using the cytobrush technique (Kasimanickam et al., 2004) and inspection of vaginal discharge using the Metricheck device (Simcro Tech Ltd., Hamilton, New Zealand; McDougall et al., 2007). Diagnostic criteria for CYTO and PVD were established based on detrimental effects on subsequent reproductive performance, and were reported elsewhere (Dubuc et al., 2010a). In summary, CYTO was the presence of $\geq 6 \%$ polymorphonuclear cells in endometrial cytology, whereas PVD was the presence of mucopurulent or purulent vaginal discharge.

Cows were bred exclusively by AI. All herds relied on estrous detection for their first breeding after a voluntary waiting period of $56 \pm 3$ d. If cows were not bred by $80 \pm 3 \mathrm{~d}$ after parturition, and for subsequent breeding, cows were enrolled on an ovulation synchronization program (Ovsynch, without pre-synchronization). Cow-specific information on the use of synchronization and timed AI was not recorded, but estrous detection was the primary means of first AI in these herds. The distribution of AI by days of the week was examined to estimate the proportion of first AI performed with synchronization in each herd. Reproductive data were collected until 300 DIM or until the date of culling, if earlier. Pregnancy diagnosis was performed by transrectal palpation between 35 and 49 d after last AI.

\section{Statistical Analyses}

Individual cow data were recorded on farm with DairyComp 305 (Valley Agricultural Software, Tulare, CA). These data were exported to Microsoft Excel (Microsoft Corp., Richmond, WA). Statistical analyses were performed with SAS (Version 9.2; SAS Institute Inc., Cary, NC) considering the cow as the experimental unit. A dummy variable with 4 categories (controlcontrol, control-prostaglandin, ceftiofur-control, and ceftiofur-prostaglandin) was created to describe experimental treatment (Dubuc et al., 2011).

Prepartum and postpartum serum concentrations of NEFA, BHBA, and HAPTO were reported as continuous variables. Dichotomization of these values was performed for each metabolite within each week sampled. Threshold selection was based on the highest sum of sensitivity and specificity for predicting the occurrence of anovulation to a given time point. Body condition scores were classified as fat $(\geq 3.75)$, moderate (3.0 to $3.5)$, or thin $(\leq 2.75)$.

Progesterone data were dichotomized using a threshold of $1 \mathrm{ng} / \mathrm{mL}$ for indicating the presence of an active corpus luteum (Stevenson et al., 2006). Cows were considered anovulatory from parturition until the first progesterone measurement $>1 \mathrm{ng} / \mathrm{mL}$. Cows were classified as being anovulatory at 21 (Anov21), 35 (Anov35), 49 (Anov49), and 63 (Anov63) DIM. Univariable Cox proportional hazard models were used to test the association between postpartum anovulation period and time to pregnancy (PHREG procedure; considering herd as strata to account for clustering). Similar hazard ratios were found for Anov21, Anov35, Anov49, and Anov63, and cows were further classified according to their ovulatory status as having luteal function at 21 DIM (Cyc21), as having low P4 at 21 DIM but having luteal function at least once at 35 or 49 or 63 DIM (Cyc63), or being Anov63 (no samples with $\mathrm{P} 4>1 \mathrm{ng} / \mathrm{mL})$. Frequency of culling was compared between categories using a chi-squared test (FREQ procedure).

Factors associated with early postpartum ovulation $(\mathrm{Cyc} 21)$ and prolonged postpartum anovulation (Anov63) were analyzed independently. Predictor variables considered were NEFA, BHBA, HAPTO, BCS, season, parity group, peripartum events (twin, dystocia, RP, and metritis), and 305-d milk production projection (accounting for DIM at first DHIA test day). 
Experimental treatment in the clinical trial and risk category for uterine disease were forced into all models. Univariable associations between predictors and ovulatory status were tested (Pearson chi-squared; FREQ procedure). Variables with $P<0.15$ were retained and analyzed in multivariable mixed logistic regression models where herd was treated as a random effect and all 2 -way interaction terms in the final model were tested (GLIMMIX procedure). A manual backward elimination procedure was used until only significant variables or interactions were retained $(P<0.05)$. Least squares means of adjusted prevalence of anovulation were obtained for variables retained in the final models. If a 2 -way interaction containing a categorical variable with more than 2 categories was retained in the final model, similar categories were merged based on $t$-test results $(P>0.10)$.

Multivariable linear mixed models (MIXED procedure) accounting for repeated measures were used to compare serum NEFA, BHBA, and HAPTO between various ovulatory categories (Cyc21, Cyc63, and Anov63). Concentrations of NEFA, BHBA, and HAPTO were considered as the outcomes (continuous variable) in these models. Predictors offered to the models included ovulatory categories (Cyc21, Cyc63, and Anov63), BCS, season, parity group, peripartum events and diseases (twins, dystocia, RP, and metritis), 305-d milk production projection and DIM at first test day, and all 2-way interactions. Experimental treatment and risk level for uterine disease were forced into all models. A manual backward elimination procedure was used to build models until only significant variables $(P<0.05)$ were retained. Least squares means of NEFA, BHBA, and HAPTO were obtained for variables retained in the final models.

For quantifying the effect of ovulatory status on reproductive performance, first-service pregnancy risk (FSPR), time to first AI, and time to pregnancy were the outcomes. A multivariable mixed logistic regression model (GLIMMIX procedure) considering herd as a random effect was used for FSPR. Predictors offered to the model included NEFA, BHBA, HAPTO, BCS, season, parity group, peripartum events and diseases (twins, dystocia, RP, and metritis), CYTO, PVD, 305$\mathrm{d}$ milk production projection DIM at first AI, and all 2-way interactions. Experimental treatment and risk level for uterine disease were forced into the model. A backward elimination procedure was used until only significant predictors or interactions were retained $(P$ $<0.05)$. Least squares means of adjusted anovulation prevalence were obtained for variables retained in the final models. If a 2-way interaction containing a categorical variable with more than 2 categories was retained in the final model, similar categories were merged based on $t$-test results $(P>0.10)$. Multivariable Cox proportional hazard models (PHREG procedure) were used for evaluating the effect of ovulatory status (Cyc21, Cyc63, and Anov63) on time to first AI (up to 100 DIM) and on time to pregnancy (up to 300 DIM). Herds were treated as strata to account for clustering (Gröhn et al., 1998). The assumption of the proportionality of hazard of the model was assessed graphically by plotting the logarithm of the hazard function by the logarithm of the time. If a predictor did not have a proportional hazard over time, an interaction term of the $\log$ time at risk and the predictor was forced into the model (Dohoo et al., 2003).

Time to culling up to 300 DIM was used to quantify the effect of prolonged anovulation on culling. A multivariable Cox proportional hazard model (PHREG procedure) considering herds as strata (Gröhn et al., 1998) was used. Model building and validation strategies were identical to time to first AI and time to pregnancy. Median days to first service or to pregnancy were obtained from Kaplan-Meier models (LIFETEST procedure). Survival plots were generated using SigmaPlot 11 (Systat Software Inc., San Jose, CA).

\section{RESULTS}

A total of 2,178 cows were enrolled in the study. Only 2,134 cows were used for these statistical analyses because 44 cows were culled before 21 DIM. Average parity and milk production (305 d) of cows enrolled were $2.4 \pm 1.5$ lactations (mean $\pm \mathrm{SD}$ ) and 11,571 \pm $2,437 \mathrm{~kg}$ per cow, respectively. The proportion of cows with serum P4 $>1 \mathrm{ng} / \mathrm{mL}$ was $28.2 \%(\mathrm{n}=601)$ at 21 DIM, 45.1\% $(\mathrm{n}=961)$ at 35 DIM, 63.0\% $(\mathrm{n}=1,345)$ at 49 DIM, and $64.1 \%(\mathrm{n}=1,367)$ at 63 DIM. The prevalence of cows with consistently low P4 until 35, 49 , and 63 DIM was $44.4 \%(\mathrm{n}=947), 26.2 \%(\mathrm{n}=559)$, and $16.9 \%(\mathrm{n}=361)$, respectively. The association of anovulation period with time to pregnancy (hazard ratio, $\mathbf{H R}$ ) was similar for all categories of duration of anovulation (Anov21, Anov35, Anov49, and Anov63) in cows of first lactation $(\mathrm{n}=745$; Anov21: $\mathrm{HR}=0.95$, $P=0.94 ;$ Anov35: $\mathrm{HR}=0.90, P=0.22 ;$ Anov49: $\mathrm{HR}$ $=0.91, P=0.18$; and Anov63: $\mathrm{HR}=0.93, P=0.38)$, second lactation $(\mathrm{n}=629$; Anov21: $\mathrm{HR}=0.93, P=$ 0.76; Anov35: $\mathrm{HR}=0.89, P=0.18$; Anov49: $\mathrm{HR}=$ $0.92, P=0.24$; and Anov63: HR $=0.91, P=0.29)$, and third lactation or more $(\mathrm{n}=760$; Anov21: $\mathrm{HR}=$ 0.62, $P<0.01$; Anov35: $\mathrm{HR}=0.69, P<0.01$; Anov49: $\mathrm{HR}=0.74, P<0.01$; and Anov63: HR $=0.70, P<$ $0.01)$. Therefore, $28.2 \%(\mathrm{n}=601)$ of cows were classified as Cyc21, 54.9\% ( $\mathrm{n}=1,172)$ as Cyc63, and 16.9\% 
$(\mathrm{n}=361)$ as Anov63. Frequency of culling $(P=0.43)$ and culling reasons $(P=0.75)$ did not differ between anovulation status categories.

Risk factors associated with early postpartum ovulation (Cyc21) and prolonged postpartum anovulation (Anov63) are presented in Tables 1 and 2, respectively. Effects of treatment $(P>0.60)$ and risk level of uterine disease at enrollment $(P<0.01)$ were forced into the final models. Accounting for treatment, risk level of uterine disease, season, parity group, and BCS at enrolment, serum NEFA, BHBA, and HAPTO concentrations were associated with ovulatory status (Cyc21, Cyc63, or Anov63). Least squares means of NEFA, BHBA, and HAPTO stratified by ovulatory status are reported in Figures 1, 2, and 3, respectively. Cows with early postpartum ovulation had lower NEFA concentrations from $1 \mathrm{wk}$ before to $3 \mathrm{wk}$ after parturition, lower BHBA concentrations through wk 1 to 3 postpartum, and lower HAPTO concentrations through wk 1 to 2 postpartum than cows with a longer period of anovulation. The interaction term of ovulatory status and week was not significant $(P>0.20)$ in all models. Body condition score at calving and at 63 DIM were not different $(P>0.20)$ among groups in all models.

The median interval from calving to first AI was 74.4 d. Based on estimation from the distribution of AI by day of the week, approximately $21 \%$ (between 15 and $30 \%$ among herds) of first AI were done with Ovsynch for cows that had not been detected in estrus by 80 DIM. Accounting for treatment $(P=0.78)$, the risk level of uterine disease at enrolment $(P<0.01)$, and projected 305-d milk production $(P<0.01)$ effects, the time to first AI was influenced by ovulatory status (Table 3), but the latter had no effect on FSPR after accounting (Cyc21: 28.8\%; Cyc63: 30.0\%; and Anov63: $30.4 \% ; P=0.73$ ) or not (Cyc21: $33.5 \%$; Cyc63: $34.4 \%$; and Anov63: $34.3 \% ; P=0.93)$ for reproductive tract disease (CYTO and PVD) and time to first AI. Cows that were anovulatory at 63 DIM had an increased time to pregnancy up to 300 DIM, but this effect was modulated by parity group (Table 4 ). Parity group effect on time to pregnancy was similar for first- and second-parity cows $(P=0.54)$, but was greater for cows of third parity or greater $(P=0.01)$. Survival curves for time to pregnancy up to 300 DIM relative to ovulatory status (Cyc21, Cyc63, or Anov63) are presented by parity group (first and second, or third or greater) in Figures 4 and 5, respectively.

The proportion of cows culled by 300 DIM was $8.6 \%$ among Cyc21, $10.6 \%$ in Cyc63, and $20.3 \%$ in Anov63. Accounting for projected milk production level in early lactation $(P<0.01)$, parity group $(P<0.01)$, treatment $(P=0.92)$, risk level of uterine disease at enrolment $(P<0.01)$, and pregnancy status $(P=0.01)$, time to culling up to 300 DIM was decreased for Anov63 compared with Cyc21 (HR: 1.38; 95\% CI: 1.04-1.83; $P$ $=0.02$ ), but no difference was detected between Cyc63 and Cyc21 (HR: 0.89; 95\% CI: $0.65-1.23 ; P=0.49$ ).

\section{DISCUSSION}

As expected, approximately $30 \%$ of cows had ovulated by 21 DIM. Although it is known that the prevalence of anovulation at 60 DIM varies considerably between

Table 1. Final multivariable logistic regression model of factors associated with early postpartum ovulation (serum progesterone $>1 \mathrm{ng} / \mathrm{mL}$ at $21 \pm 3$ DIM; Cyc21) accounting for the random effect of herd and fixed effect of experimental treatment in 2,134 Holstein cows

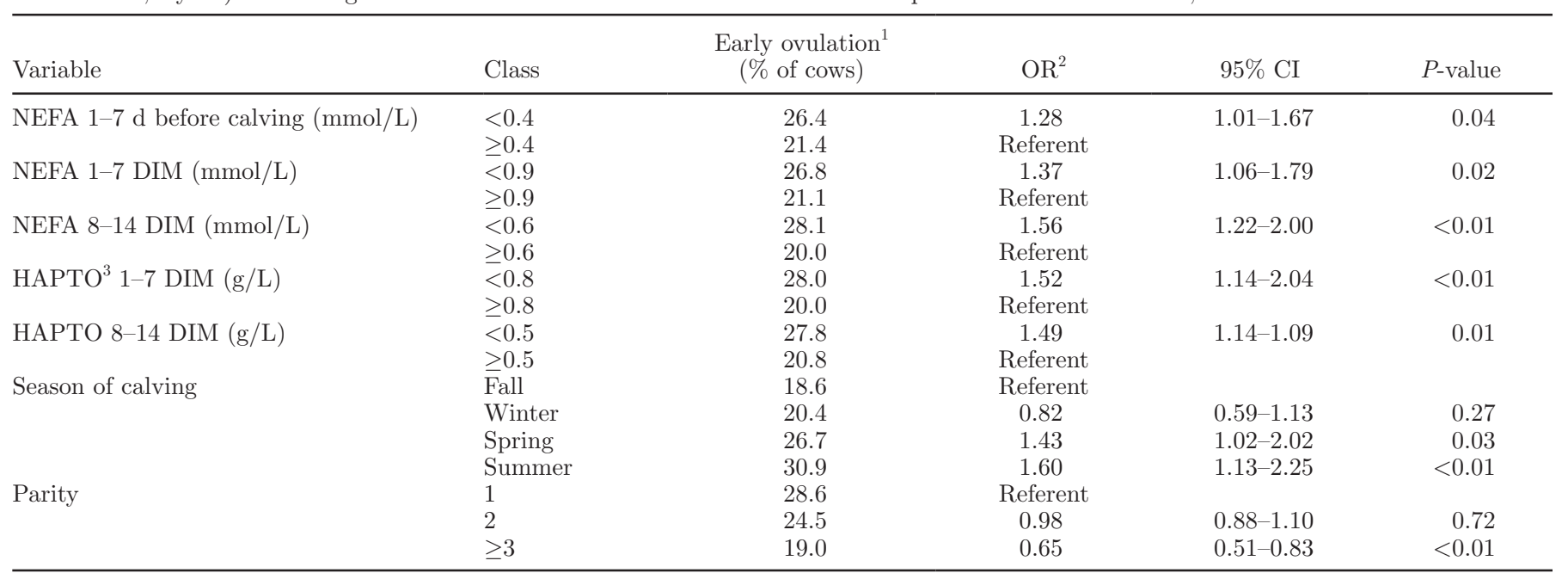

${ }^{1}$ Least squares means; early ovulation is defined as serum progesterone $>1 \mathrm{ng} / \mathrm{mL}$ at $21 \pm 3 \mathrm{DIM}$.

${ }^{2}$ Odds ratio.

${ }^{3}$ Serum haptoglobin concentration. 


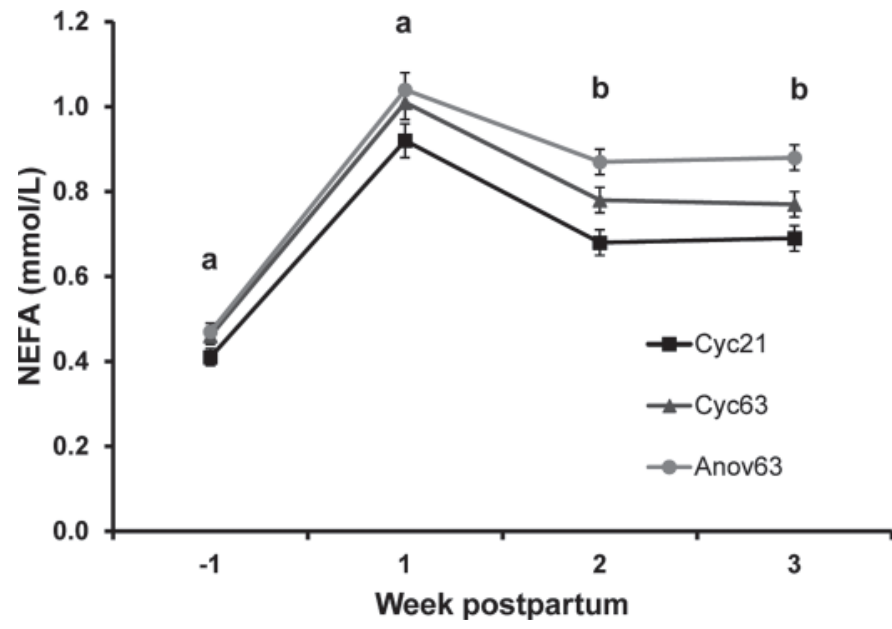

Figure 1. Mean $( \pm \mathrm{SE})$ postpartum NEFA serum concentrations in 2,134 Holstein cows stratified by postpartum ovulatory status (Cyc21: progesterone $>1 \mathrm{ng} / \mathrm{mL}$ at 21 DIM; Cyc63: progesterone $\leq 1 \mathrm{ng} / \mathrm{mL}$ at $21 \mathrm{DIM}$, but $>1 \mathrm{ng} / \mathrm{mL}$ at least once at 35,49 , or $63 \mathrm{DIM}$; and Anov63: progesterone $\leq 1 \mathrm{ng} / \mathrm{mL}$ at $21,35,49$, and $63 \mathrm{DIM})$. Letters indicate which groups are statistically different from each other: a indicates that Cyc21 is different $(P<0.05)$ from Cyc63 and Anov63, but that Cyc63 is not different $(P \geq 0.05)$ from Anov63; b indicates that all are different from each other $(P<0.05)$.

herds (Walsh et al., 2007), data from the current study suggest that anovulation in the late postpartum period was 5 to $10 \%$ lower than in other studies (Walsh et al., 2007; Santos et al., 2009; Galvão et al., 2010). But, because participating cows were enrolled in the clinical trial based on a case-control selection approach (with and without peripartum risk factors; Dubuc et al., 2011), such overall prevalence of anovulation in the study was not representative of enrolled herds and should not be used to compare with other stud-

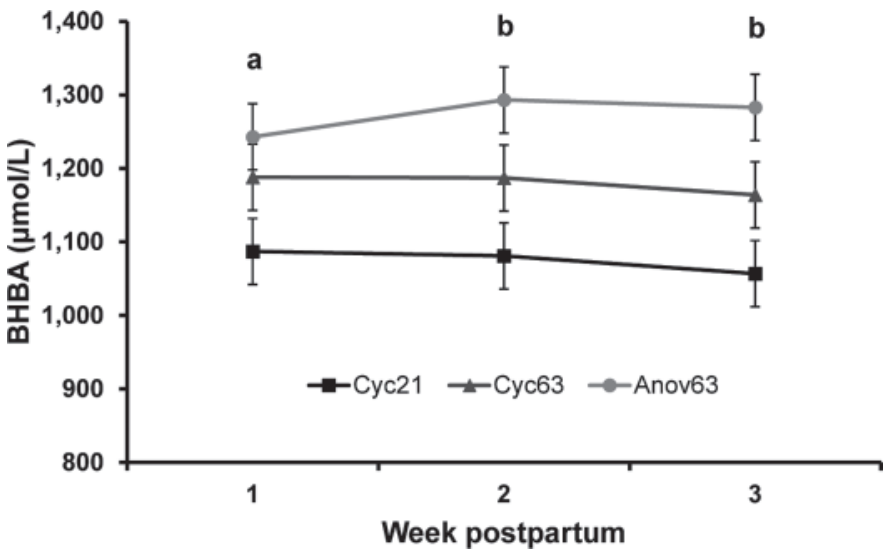

Figure 2. Mean $( \pm \mathrm{SE})$ postpartum BHBA serum concentration in 2,134 Holstein cows stratified by postpartum ovulatory status (Cyc21: progesterone $>1 \mathrm{ng} / \mathrm{mL}$ at 21 DIM; Cyc63: progesterone $\leq 1 \mathrm{ng} / \mathrm{mL}$ at $21 \mathrm{DIM}$, but $>1 \mathrm{ng} / \mathrm{mL}$ at least once at 35,49 , or $63 \mathrm{DIM}$; and Anov63: progesterone $\leq 1 \mathrm{ng} / \mathrm{mL}$ at $21,35,49$, and 63 DIM). Letters indicate which groups are statistically different from each other: a indicates that Cyc21 is different $(P<0.05)$ from Cyc63 and Anov63, but that Cyc63 is not different $(P \geq 0.05)$ from Anov63; b indicates that all are different from each other $(P<0.05)$.

ies investigating the prevalence of anovulation in dairy herds (random sampling of general herd population). As expected and shown elsewhere (Dubuc et al., 2011), experimental treatment had no effect on reproductive performance and culling.

As hypothesized, factors associated with early ovulation or prolonged anovulation included indicators of energy balance, uterine inflammation, season, parity, and milk production level. Elevated peripartum NEFA concentrations were associated with lower probability of early ovulation. Elevated NEFA circulation in serum may be indicative of decreased DMI and greater nega-

Table 2. Final multivariable logistic regression model of factors associated with prolonged postpartum anovulation (no serum progesterone samples $>1 \mathrm{ng} / \mathrm{mL}$ at 21, 35, 49, and 63 DIM; Anov63) accounting for the random effect of herd and fixed effect of experimental treatment in 2,134 Holstein cows

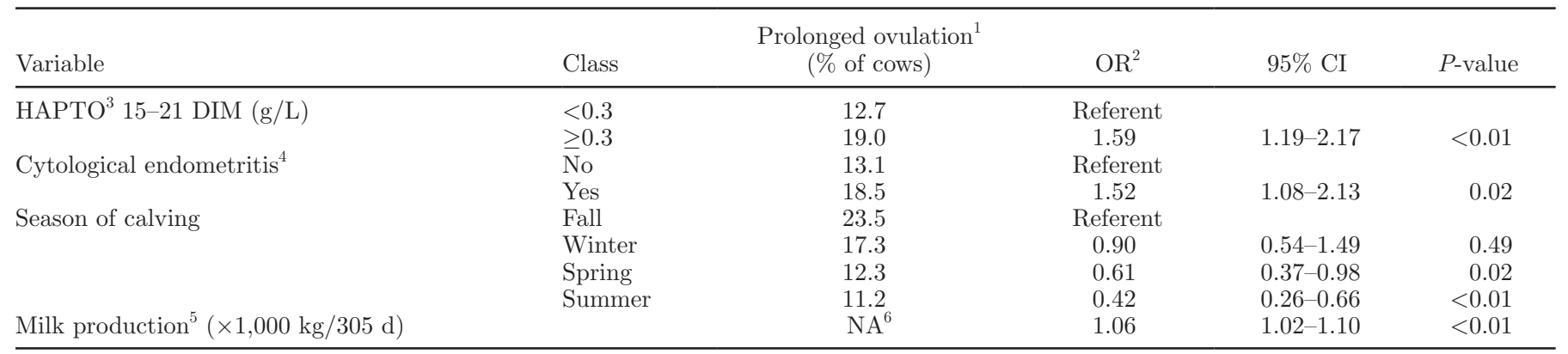

${ }^{1}$ Least squares means; prolonged anovulation is defined as no serum progesterone samples $>1 \mathrm{ng} / \mathrm{mL}$ at $21,35,49$, and 63 DIM.

${ }^{2}$ Odds ratio.

${ }^{3}$ Serum haptoglobin concentrations.

${ }^{4} \geq 6 \%$ polymorphonuclear cells in endometrial cytology at 35 DIM.

${ }^{5}$ Projection at first DHIA test day.

${ }^{6}$ Not available, continuous variable. 
Table 3. Final Cox proportional hazard model of factors associated with time to first service (insemination hazard) up to 100 DIM accounting for the fixed effect of experimental treatment in 2,134 Holstein cows

\begin{tabular}{|c|c|c|c|c|c|c|c|}
\hline Predictor & Class & $\begin{array}{l}\text { Median time to } \\
\text { first AI (d) }\end{array}$ & Coefficient & $\mathrm{SE}$ & $\mathrm{HR}^{1}$ & $95 \%$ CI & $P$-value \\
\hline \multirow[t]{2}{*}{ Parity } & 1 & 73.2 & Referent & & & & \\
\hline & $\geq 3$ & 74.1 & -0.21 & 0.09 & 0.85 & $0.70-1.02$ & 0.05 \\
\hline \multirow[t]{3}{*}{ Ovulatory status } & $\overline{\mathrm{Cyc}} 21^{2}$ & 72.8 & Referent & & & & \\
\hline & Cyc63 $3^{3}$ & 73.2 & 0.00 & 0.01 & 1.00 & $0.91-1.11$ & 0.98 \\
\hline & Anov $63^{4}$ & 74.1 & -0.13 & 0.03 & 0.88 & $0.78-0.99$ & 0.04 \\
\hline
\end{tabular}

${ }^{1}$ Hazard ratio; HR $<1$ indicates a reduced daily relative risk of pregnancy; HR $>1$ indicates an increased daily relative risk of pregnancy.

${ }^{2}$ Cows with serum progesterone $>1 \mathrm{ng} / \mathrm{mL}$ at 21 DIM.

${ }^{3}$ Cows with serum progesterone $\leq 1 \mathrm{ng} / \mathrm{mL}$ at 21 DIM and at least 1 serum progesterone $>1 \mathrm{ng} / \mathrm{mL}$ at 35,49 , or 63 DIM.

${ }^{4}$ Cows with serum progesterone $\leq 1 \mathrm{ng} / \mathrm{mL}$ at all of $21,35,49$, and 63 DIM.

${ }^{5}$ Projection at first DHIA test day.

${ }^{6}$ Not available, continuous variable.

tive energy balance. Increased severity of negative energy balance and increased time to its nadir decreased the probability of ovulation by 21 DIM (Beam and Butler, 1998; Bossaert et al., 2008). This phenomenon may be mediated through lower concentrations of IGF-1 and estradiol in cows that do not ovulate by 21 DIM (Beam and Butler, 1998). Although hyperketonemia was associated with lower probability of ovulation by 21 DIM in univariable analysis, it was not retained in the final multivariable model after accounting for NEFA concentration. Presumably, NEFA is more closely associated with early ovulation than hyperketonemia. Prolonged

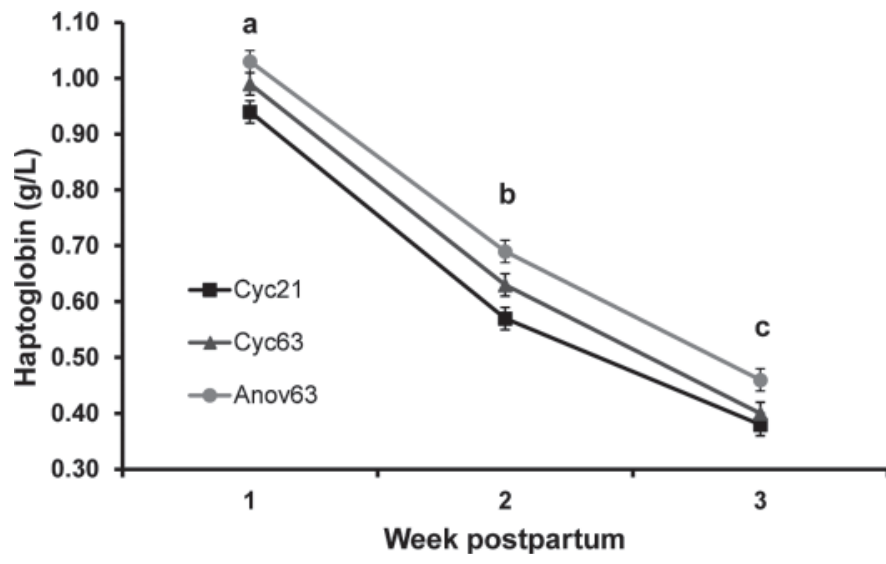

Figure 3. Mean $( \pm \mathrm{SE})$ postpartum haptoglobin serum concentration in 2,134 Holstein cows stratified by postpartum ovulatory status (Cyc21: progesterone $>1 \mathrm{ng} / \mathrm{mL}$ at 21 DIM; Cyc63: progesterone $\leq 1$ $\mathrm{ng} / \mathrm{mL}$ at 21 DIM, but $>1 \mathrm{ng} / \mathrm{mL}$ at least once at 35,49 , or 63 DIM; and Anov63: progesterone $\leq 1 \mathrm{ng} / \mathrm{mL}$ at 21, 35, 49, and 63 DIM). Letters indicate which groups are statistically different from each other: a indicates that Cyc21 is different $(P<0.05)$ from Cyc63 and Anov63, but that Cyc63 is not different $(P \geq 0.05)$ from Anov63; b indicates that all are different from each other $(P<0.05)$; c indicates that Anov63 is different $(P<0.05)$ from $\mathrm{Cyc} 21$ and Cyc63, but that Cyc21 is not different $(P \geq 0.05)$ from Cyc63. postpartum anovulation was associated with greater serum NEFA and BHBA concentrations. Although these associations may not be causal, they support the notion that increased severity of negative energy balance is associated with a greater risk of prolonged anovulation (Beam and Butler, 1998).

Elevated HAPTO concentration during the postpartum period was associated with a longer period of anovulation. Hyperhaptoglobinemia was a predictor for metritis and uterine inflammation (Huzzey et al., 2009; Dubuc et al., 2010b). A mechanistic interpretation of the association of HAPTO with reproductive tract disease or with anovulatory status is not clear. A heightened general state of inflammation during the early postpartum period may reflect a decreased adaptive response against infection and proinflammatory effects of lipid mobilization (Sordillo et al., 2009).

Cows of third parity or greater had lower probability of early ovulation than cows of first and second parity, which supports a previous report (Opsomer et al., 1998), but contrasts another (Santos et al., 2009). Greater first DHIA 305-d milk production projection was associated with slightly greater odds of anovulation at 63 DIM in the current study, somewhat in contrast to Walsh et al. (2007) who found no association of projected production $>9,500 \mathrm{~kg}$ with anovulation, but increased odds of anovulation as production decreased below $9,500 \mathrm{~kg}$.

Postpartum ovulatory status influenced time to first $\mathrm{AI}$ in these herds relying primarily on estrous detection from 56 to 80 DIM. Anovulation at 63 DIM had no effect on the odds of pregnancy at first AI, which is different from previous reports (Walsh et al., 2007; Galvão et al., 2010). Presumably, the management protocols in which cows were enrolled in an ovulation synchronization protocol if not detected in estrus and bred by 80 DIM shortened time to first AI of cows with prolonged 


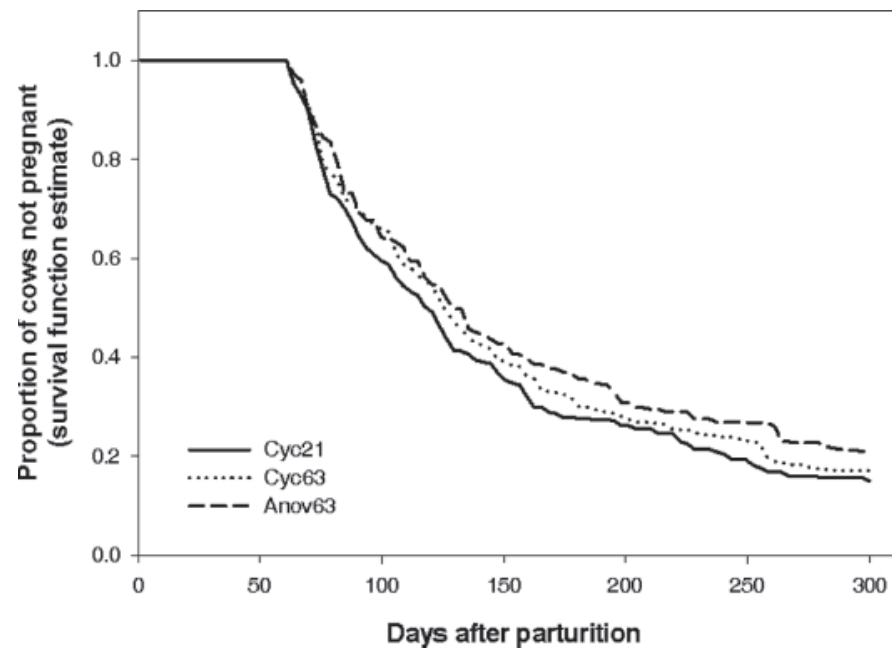

Figure 4. Survival curves for time to pregnancy up to 300 DIM in 1,376 Holstein cows of first or second parity stratified by postpartum ovulatory status (Cyc21: progesterone $>1 \mathrm{ng} / \mathrm{mL}$ at 21 DIM; Cyc63: progesterone $\leq 1 \mathrm{ng} / \mathrm{mL}$ at $21 \mathrm{DIM}$, but $>1 \mathrm{ng} / \mathrm{mL}$ at least once at 35, 49, or 63 DIM; and Anov63: progesterone $\leq 1 \mathrm{ng} / \mathrm{mL}$ at 21, 35, 49, and $63 \mathrm{DIM})$. Median days to pregnancy (95\% CI; n; $P$-value) were $118(111-125 ; \mathrm{n}=399$; referent), $126(117-135 ; \mathrm{n}=677 ; P=0.32)$, and $128(120-136 ; \mathrm{n}=198 ; P=0.21)$ for Cyc21, Cyc63, and Anov63, respectively.

anovulation (Gümen et al., 2003; McDougall, 2010). Time to pregnancy up to 300 DIM was increased in cows with later or no ovulation by 63 DIM (Cyc63 or Anov63) compared with Cyc21, but this effect was conditional on parity group: a detrimental effect was only

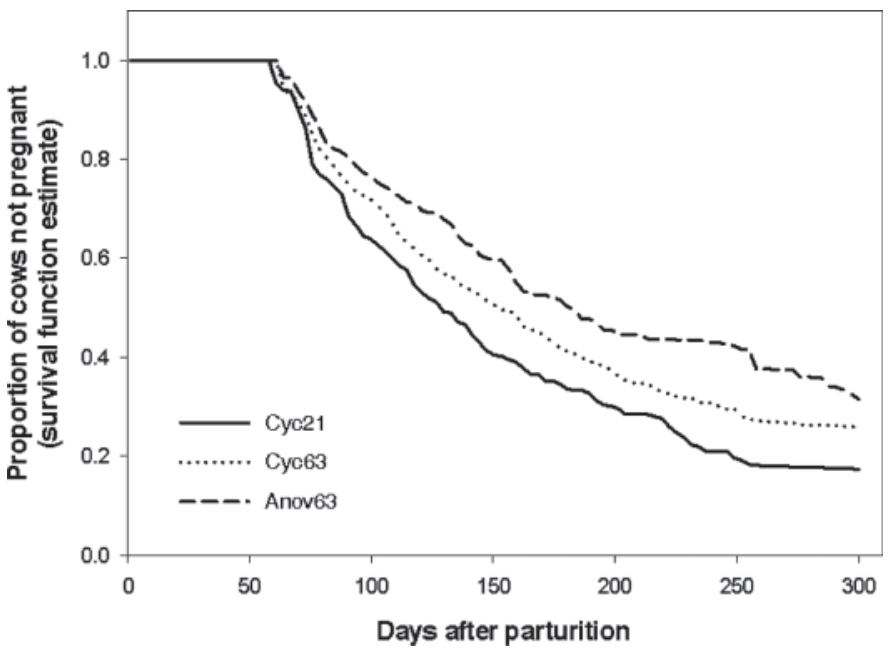

Figure 5. Survival curves for time to pregnancy up to 300 DIM in 758 Holstein cows of third parity or greater stratified by postpartum ovulatory status (Cyc21: progesterone $>1 \mathrm{ng} / \mathrm{mL}$ at 21 DIM; Cyc63: progesterone $\leq 1 \mathrm{ng} / \mathrm{mL}$ at $21 \mathrm{DIM}$, but $>1 \mathrm{ng} / \mathrm{mL}$ at least once at 35, 49, or 63 DIM; and Anov63: progesterone $\leq 1 \mathrm{ng} / \mathrm{mL}$ at 21, 35, 49, and $63 \mathrm{DIM})$. Median days to pregnancy $(95 \% \mathrm{CI} ; \mathrm{n} ; P$-value) were $129(119-137 ; \mathrm{n}=152 ;$ referent), $151(143-164 ; \mathrm{n}=437 ; P<0.01)$, and $180(169-191 ; \mathrm{n}=112 ; P<0.01)$ for Cyc21, Cyc63, and Anov63, respectively.

present in cows of third parity or more. In these cows, Cyc63 and Anov63 were associated with $22(P<0.01)$ and $51(P<0.01)$ d longer median time to pregnancy than Cyc21, respectively. A similar study investigating the effects of anovulation up to 49 DIM did not report

Table 4. Final Cox proportional hazard model of factors associated with time to pregnancy (pregnancy hazard) up to 300 DIM accounting for the fixed effect of experimental treatment in 2,134 Holstein cows

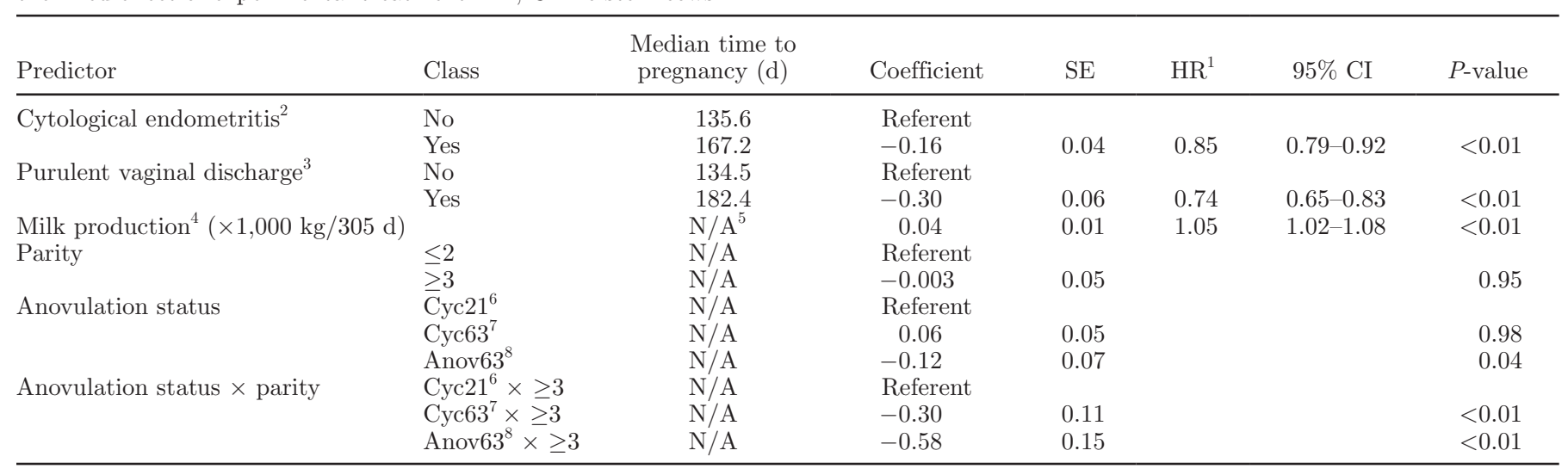

${ }^{1}$ Hazard ratio; HR $<1$ indicates a reduced daily relative risk of pregnancy; HR $>1$ indicates an increased daily relative risk of pregnancy.

${ }^{2} \geq 6 \%$ polymorphonuclear cells in endometrial cytology at 35 DIM.

${ }^{3}$ Mucopurulent or purulent vaginal discharge at 35 DIM.

${ }^{4}$ Projection at first DHIA test day.

${ }^{5}$ Not available. For parity, anovulation status, and parity by anovulation status, values are presented in Figures 4 and 5 .

${ }^{6}$ Cows with serum progesterone $>1 \mathrm{ng} / \mathrm{mL}$ at 21 DIM.

${ }^{7}$ Cows with serum progesterone $\leq 1 \mathrm{ng} / \mathrm{mL}$ at 21 DIM and at least 1 serum progesterone $>1 \mathrm{ng} / \mathrm{mL}$ at 35,49 , or 63 DIM.

${ }^{8}$ Cows with serum progesterone $\leq 1 \mathrm{ng} / \mathrm{mL}$ at all of $21,35,49$, and 63 DIM. 
such a conditional effect of parity, but reported an increase in median time to pregnancy of 44 and $70 \mathrm{~d}$ for Cyc49 (P4 $\leq 1 \mathrm{ng} / \mathrm{mL}$ at $21 \mathrm{DIM}$ and $\mathrm{P} 4>1 \mathrm{ng} / \mathrm{mL}$ at least once at 35 or 49 DIM) and Anov49 (P4 $\leq 1 \mathrm{ng} / \mathrm{mL}$ at all of 21,35 , and 49 DIM), respectively, compared with Cyc21 (Galvão et al., 2010). Even if these numbers are different, the magnitude of detrimental effect on time to pregnancy caused by prolonged anovulation was similar in both studies. These data suggest that ovulating early in the postpartum period is beneficial for subsequent reproductive performance and that prolonged anovulation is detrimental mainly in older cows.

Not surprisingly, CYTO and PVD had detrimental effects on hazard of pregnancy up to 300 DIM. Similar effects were reported using the same data (Dubuc et al., 2010a) and in other studies (LeBlanc et al., 2002; Gilbert et al., 2005; Barlund et al., 2008). The present study is one of the first to account for both reproductive diseases (CYTO and PVD) as well as the effect of anovulation on reproductive performance. Previous studies have considered CYTO or PVD independently (Opsomer et al., 2000; Burke et al., 2010; Galvão et al., 2010). By accounting for CYTO and PVD in the final Cox proportional hazard model of time to pregnancy, it implies that prolonged anovulation has a detrimental effect independent of these reproductive diseases.

Few studies have investigated the effect of postpartum ovulatory status on culling. The present results suggest that having a first ovulation early or later in the postpartum period, as long as it was no later than 63 DIM, did not influence culling risk.

A weakness of the present study is that $\mathrm{P} 4$ measurements were only performed at the minimum frequency (every $2 \mathrm{wk}$ ) to estimate ovulatory status. It is possible that at any 1 sample time, cows with low $\mathrm{P} 4$ may have been in proestrus, estrus, or early metestrus. This must be weighed against the large number of measurements collected and the number of factors examined. Another point to underline is that cows in the present analysis were in a clinical trial in which animals were purposely selected on the basis of having or not having peripartum conditions that may increase the level of risk for uterine disease. Therefore, a greater proportion of cows at high risk of uterine disease were in this sample population than in typical whole herds. Finally, reproductive performance was likely influenced by imposing an upper limit on the interval to first AI by enrolling cows on an ovulation synchronization protocol if not detected in estrus and bred by 80 DIM. Although synchronization was used in a minority of cows, this may have decreased the apparent magnitude of detrimental effect of prolonged anovulation, specifically by increasing the insemination rate of synchronized anestrous cows (McDougall, 2010); it is unclear if Ovsynch without supplemental P4 would have increased the probability of pregnancy at the synchronized AI in anovular cows (Gümen et al., 2003; McDougall, 2010)

\section{CONCLUSIONS}

Early ovulation or prolonged anovulation was associated with indicators of negative energy balance and uterine inflammation during the peripartum period, as well as milk production level, parity, and season. Ovulation by 21 DIM was associated with shorter time to pregnancy and prolonged anovulation was detrimental to subsequent reproductive performance and culling. These effects of prolonged anovulation on reproduction were worse in cows of third parity or greater and it may be relevant to apply targeted mitigation strategies to those cows.

\section{ACKNOWLEDGMENTS}

This project was financially supported by Pfizer Animal Health (New York, NY). The authors thank the farmers, veterinarians, and technical staff for their participation.

\section{REFERENCES}

Barlund, C. S., T. D. Carruthers, C. L. Waldner, and C. W. Palmer. 2008. A comparison of diagnostic techniques for postpartum endometritis in dairy cattle. Theriogenology 69:714-723.

Beam, S. W., and W. R. Butler. 1997. Energy balance and ovarian follicle development prior to the first ovulation postpartum in dairy cows receiving three levels of dietary fat. Biol. Reprod. $56: 133-142$.

Beam, S. W., and W. R. Butler. 1998. Energy balance, metabolic hormones, and early postpartum follicular development in dairy cows fed prilled lipid. J. Dairy Sci. 81:121-131.

Bossaert, P., J. L. M. R. Leroy, S. D. Vliegher, and G. Opsomer. 2008 Interrelations between glucose-induced insulin response, metabolic indicators, and time of first ovulation in high-yielding dairy cows. J. Dairy Sci. 91:3363-3371.

Burke, C. R., S. Meier, S. McDougall, C. Compton, M. Mitchell, and J. R. Roche. 2010. Relationships between endometritis and metabolic state during the transition period in pasture-grazed dairy cows. J. Dairy Sci. 93:5363-5373.

Dohoo, I., W. Martin, and H. Stryhn. 2003. Veterinary epidemiologic research. 1st ed. AVC Inc., Charlottetown, PE.

Dubuc, J., T. F. Duffield, K. E. Leslie, J. S. Walton, and S. J. LeBlanc. 2010a. Definitions and diagnosis of postpartum endometritis in dairy cows. J. Dairy Sci. 93:5225-5233.

Dubuc, J., T. F. Duffield, K. E. Leslie, J. S. Walton, and S. J. LeBlanc. 2010b. Risk factors for postpartum uterine diseases in dairy cows. J. Dairy Sci. 93:5764-5771.

Dubuc, J., T. F. Duffield, K. E. Leslie, J. S. Walton, and S. J. LeBlanc. 2011. Randomized clinical trial of antibiotic and prostaglandin treatments for uterine health and reproductive performance in dairy cows. J. Dairy Sci. 94:1325-1338.

Ferguson, J. D., D. T. Galligan, and N. Thomsen. 1994. Principal descriptors of body condition score in Holstein cows. J. Dairy Sci. $77: 2695-2703$.

Galvão, K. N., M. Frajblat, W. R. Butler, S. B. Brittin, C. L. Guard, and R. O. Gilbert. 2010. Effect of early postpartum ovulation on fertility in dairy cows. Reprod. Domest. Anim. 45:e207-e211. 
Gilbert, R. O., S. T. Shin, C. L. Guard, H. N. Erb, and M. Frajblat. 2005. Prevalence of endometritis and its effects on reproductive performance of dairy cows. Theriogenology 64:1879-1888.

Gröhn, Y. T., S. W. Eicker, V. Ducrocq, and J. A. Hertl. 1998. Effect of diseases on the culling of Holstein dairy cows in New York State. J. Dairy Sci. 81:966-978.

Gümen, A., J. N. Guenther, and M. C. Wiltbank. 2003. Follicular size and response to Ovsynch versus detection of estrus in anovular and ovular lactating dairy cows. J. Dairy Sci. 86:3184-3194.

Huzzey, J. M., T. F. Duffield, S. J. LeBlanc, D. M. Veira, D. M. Weary, and M. A. G. von Keyserlingk. 2009. Haptoglobin as an early indicator of metritis. J. Dairy Sci. 92:621-625.

Kasimanickam, R., T. F. Duffield, R. A. Foster, C. J. Gartley, K. E. Leslie, J. S. Walton, and W. H. Johnson. 2004. Endometrial cytology and ultrasonography for the detection of subclinical endometritis in postpartum dairy cows. Theriogenology 62:9-23.

LeBlanc, S. J., T. F. Duffield, K. E. Leslie, K. G. Bateman, G. P. Keefe, J. S. Walton, and W. H. Johnson. 2002. Defining and diagnosing postpartum clinical endometritis and its impact on reproductive performance in dairy cows. J. Dairy Sci. 85:2223-2236.

Martin, J. L., K. A. Vonnahme, D. C. Adams, G. P. Lardy, and R. N. Funston. 2007. Effects of dam nutrition on growth and reproductive performance of heifer calves. J. Anim. Sci. 85:841-847.

Mateus, L., L. L. d. Costa, F. Bernardo, and J. R. Silva. 2002. Influence of puerperal uterine infection on uterine involution and postpartum ovarian activity in dairy cows. Reprod. Domest. Anim. $37: 31-35$.

McCoy, M. A., S. D. Lennox, C. S. Mayne, W. J. McCaughey, H. W. J. Edgar, D. C. Catney, M. Verner, D. R. Mackey, and A. W. Gordon. 2006. Milk progesterone profiles and their relationship with fertility, production and disease in dairy cows in Northern Ireland. Anim. Sci. 82:213-222.

McDougall, S. 2010. Effects of treatment of anestrous dairy cows with gonadotropin-releasing hormone, prostaglandin, and progesterone. J. Dairy Sci. 93:1944-1959.

McDougall, S., R. Macaulay, and C. Compton. 2007. Association between endometritis diagnosis using a novel intravaginal device and reproductive performance in dairy cattle. Anim. Reprod. Sci. 99:9-23.
Opsomer, G., M. Coryn, H. Deluyker, and A. de Kruif. 1998. An analysis of ovarian dysfunction in high yielding dairy cows after calving based on progesterone profiles. Reprod. Domest. Anim. $33: 193-204$

Opsomer, G., Y. T. Gröhn, J. Hertl, M. Coryn, H. Deluyker, and A. d. Kruif. 2000. Risk factors for post partum ovarian dysfunction in high producing dairy cows in Belgium: A field study. Theriogenology 53:841-857.

Santos, J. E. P., H. M. Rutigliano, and M. F. S. Filho. 2009. Risk factors for resumption of postpartum estrous cycles and embryonic survival in lactating dairy cows. Anim. Reprod. Sci. 110:207-221.

Sheldon, I. M., J. Cronin, L. Goetze, G. Donofrio, and H.-J. Schuberth. 2009. Defining postpartum uterine disease and the mechanisms of infection and immunity in the female reproductive tract in cattle. Biol. Reprod. 81:1025-1032.

Sheldon, I. M., D. E. Noakes, A. N. Rycroft, D. U. Pfeiffer, and H. Dobson. 2002. Influence of uterine bacterial contamination after parturition on ovarian dominant follicle selection and follicle growth and function in cattle. Reproduction 123:837-845.

Skinner, J. G., R. A. L. Brown, and L. Roberts. 1991. Bovine haptoglobin response in clinically defined field conditions. Vet. Rec. $128: 147-149$.

Skinner, J. G., and L. Roberts. 1994. Haptoglobin as an indicator of infection in sheep. Vet. Rec. 134:33-36.

Sordillo, L. M., G. A. Contreras, and S. L. Aitken. 2009. Metabolic factors affecting the inflammatory response of periparturient dairy cows. Anim. Health Res. Rev. 10:53-63.

Stevenson, J. S., J. R. Pursley, H. A. Garverick, P. M. Fricke, D. J. Kesler, J. S. Ottobre, and M. C. Wiltbank. 2006. Treatment of cycling and noncycling lactating dairy cows with progesterone during Ovsynch. J. Dairy Sci. 89:2567-2578.

Walsh, R. B., D. F. Kelton, T. F. Duffield, K. E. Leslie, J. S. Walton, and S. J. LeBlanc. 2007. Prevalence and risk factors for postpartum anovulatory condition in dairy cows. J. Dairy Sci. 90:315-324.

Williams, E. J., D. P. Fischer, D. E. Noakes, G. C. W. England, A. Rycroft, H. Dobson, and I. M. Sheldon. 2007. The relationship between uterine pathogen growth density and ovarian function in the postpartum dairy cow. Theriogenology 68:549-559. 